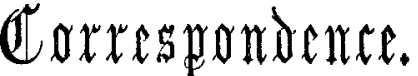

\section{"Audi alteram partem."}

\section{CHEYNE-STOKES RESPIRATION.}

\section{To the Editors of THE LANCET.}

SIRS,-In reply to Dr. Stephen Mackenzie's request at the Clinical Society for reports of cases in which patients had developed Cheyne-Stokes respiration and recovered, I send notes of two. The first case occurred six years ago and the second in the early part of 1888 ; both of the patients $I$ have seen to-day in perfect health. The case which occurred six years ago was that of a boy five years of age; he was taken one afternoon with epileptiform convulsions. Temperature rose to $103^{\circ}$; pulse irregular. The Cheyne-Stokes respiration lasted four hours, during which time there were two or three violent attacks of convulsions lasting from a quarter to half an hour, for which I administered chloroform. On recovering frorn each fit the characteristic breathing was resumed. The following morning the temperature fell to normal, and the breathing resumed its ordinary character.

The second case occurred two years ago in a child of my own aged four months, and was seen daily by Dr. De Havilland Hall for some time. In this case the illness commenced with the signs of meningeal mischief, and after the child had been ill nearly a week Cheyne-Stokes respiration commenced, and continued for four days. The pauses which occurred sometimes between ten respirations (sometimes many more) were particularly well marked, lasting from tive to ten seconds, then the respiration would commence with a deep inspiration which gradually became less frequent and more shallow until another pause came. The temperature before the special breathing was noticed was raised, but afterwards was mostly subnormal; convulsive attacks occurred at intervals for several days, and squinting, which commenced a few days from the beginning of the illness, persisted for several weeks. During the time the Cheyne-Stokes respiration lasted the fontanelles became much depressed, and remained so for two weeks. After the more acute cerebral symptoms ceased hydrocephalus developed, with consequent bulging of the fontanelles and opening of the sutures; these symptoms ceased to increase after six weeks, and although the head is more square than normal and slightly larger, it has long since ceased to grow out of proportion to the other parts of the body, and perfect bealth has been maintained.

I am, Sirs, yours truly, JoHN ADAMS, F.R.C.S

Aldersgate-street, E.C., March 17th, 1890.

\section{To the Editors of THE LANCET.}

SIRS,-In reference to the correspondence elicited by Dr. Stephen Mackenzie's question as to the possibility of recovery after the development of Cheyne-Stokes respiration, the following case may be of interest to your readers. On Thursday, the 6 th inst., I was summoned to attend a lady, aged twenty.six, who had been under my care for some weeks suffering from advanced phthisis. I found her retching violently, and complaining of extreme pain in both infra-clavicular regions. In a few minutes she became violently delirious, but this soon passed off, and retching, together with extreme pain, came on as before. I injected subcutaneously inj. morph. hypod. (B.P.) in iii. The patient soon became quiet, and lay as if asleep for about ten minutes. The pulse, which had hitherto been fairly good, although frequent, gradually became smaller, until it was barely perceptible at the wrist. At the same time the respiration began to be irregular, and soon came a long pause. The pause was succeeded by a deep sighing respiration; then followed succeeding respirations with increasing rapidity, until the rate exceeded sixty per minute. The rate then gradually diminished down to a pause so long as to make it seem that respiration had entirely ceased. This kind of breathing continued for more than an hour, during which time the patient lay unconscious except for a few lucid intervals of a few seconds each. Ether was administered hypodermically four times. After each there was marked improvement in the pulse, but it was only permanent after the fourth injection. With the final improvement in the pulse the respirations gradually resumed their usual character. The patient seemed to rouse herself and recognised her friends. She then fell into a natural sleep, which lasted nearly four hours, from which she awoke quite conscious, free from pain, but feeling exhausted. She is now in practically the same condition as before the attack twelve days ago.

I am, Sirs, yours faithfully, Walter C. AYLWird, M.R.C.S. \&C.

Rusthall, Tunbridge Wells, March 18th, 1890.

\section{THE HOSPITAL SATURDAY FUND AND HOSPITAL ABUSES.}

\section{To the Editors of THE LANCET.}

SIRs,--Your weighty editorial article on the above must command attention. Impure charity is now the rage. Efforts are being made to sell charity and to convert our hospitals into "commercial concerns." It has been decided that a man has no right to claim Poor-law relief unless he can prove destitution, no matter if he has paid hundreds of pounds in rates. The same should hold good in hospital administration. It seems that the managers of medical charities are determined by their blundering to compel the State to take over their control. Two commissions to inquire into hospital management have already been asked for.

As to the working men asking a quid pro q210, this is not to be wondered at. Are not the half-guinea and guinea subscribers given so many tickets of recommendation for each sum sent? Query: If a "gentleman" secure five tickets for $20 \mathrm{~s}$., how many should a " working man " obtain for $4 s$ ? Why, one. Of course the selling of charity to any person whomsoever is false. But who began it? The mora is : cease giving "tickets of recommendation" to any subscriber. In Birmingham they sell six tickets for $10 s .6 d$., each ticket giving treatment and medicine for six weeks, renew. able by paying $3 s .6 d$. Happy and charitable Birmingham: Fifteen per cent. philanthropy is the most paying " job" after all. The cent. per-cent. gentry could hardly exceed such charitable, benevolent, and disinterested work. Yet who started the plan? A doctor. Who carries it on? Why, the doctors. Truly many of us are a most Christ-like pro. fession-but in professing only. We calmly stand by and see the very groundwork of private charity ignored, and meekly watch a splendid system of voluntary relief to the sick poor prostituted. I think it is little wonder that even hospital committees are kicking the medical staffs off, and refusing to associate with them. No doubt, as we make our bed so shall we lie on it. The battle now seems to be be. tween the one penny hospital doctor and the sixpenny dispensary doctor. Which will win? Why, the one who offers his goods at the lowest market price. For my own part, prefer the sixpenny doctor. He is what he is, and does not pretend to much. He does not blow his charitable horn in the market place, or decorate his "shop" and reports with Bible quotations. - I arn, Sirs, yours faithfully, Liverpool, March, 1890

Robt. R. Rentout.

\section{To the Editors of THE LANCET.}

SIRs,-We all owe you our best thanks for your leading article on the Cnreasonable Demands of Hospital Saturday Fund Promoters, and your remarks elsewhere on the Growth of Out-patient Departments. The amount of the Saturday Fund is in itself so paltry that it would make but small difference to the hospitals if it were discontinued altogether. It has, moreover, the overwhelming objection that it leads those who contribute to is to imagine they are providing for themselves in case of sickness, and it utterly eradicates all self-esteem, and any feeling of hesitation the working-classes may have to seek medical charity on the most trifling occasion, while the idea of gratitude does not of course enter into a business transaction. The general public does not realise how infinitely small is the amount thus contributed compared with the annual donations, by means of which the hospitals are chiefly maintained-it being, in fact, a mere drop in the ocean.

The Hospital Sunday Fund has also much to answer for in a somewhat different way. It is the aim and object of the management to encourage and magnify by every possible means the attendances in the out-patient department. Upon this number depends to a considerable extent the share in the annual division. Hence both funds each in a 
way do more harm than good, and directly encourage the system of abuse which is now so greatly exercising the minds of all interested in this matter. I would suggest an alteration in the basis of division, disregarding altogether out-patients and their attendances; one reason for boasting in this particular would be eliminated, aud a considerable change would soon be noticed in hospital statisties. I am, Sirs, yours faithfully, J. A. Mansell Mouluis.

Wimpole-street, W., March 15th, 1890.

* * Our correspondent is in error in thinking that the Hospital Sunday Fund has anything in its system of awards which favours the mushroom-like growth of the out-patient departments. This system is based on the average total expenditure for three years, with certain deductions for legacies, income from investments, \&c. There is a slight discretionary power in the Distribution Committee in the judgment of merits and needs: but the high numbers of out-patients constitute neither merit nor need. In the Hospital Saturday system the capitation principle is still maintained.-ED. L.

\section{TREATMENT OF VITREOUS OPACITIES.} To the Editors of THE LANCET.

SIRS, - In my letter which you kindly published in your issue of March 8th, I inferred that serum effused to take the place of lost vitreous only remained transparent for a short time. Mr. Ford replies that " this is contrary to the experience derived from cataract extractions followed by loss of large amounts of vitreous, which in many cases yield good and permanent results." On this point I am quite at variance with your correspondent; my experience is that fluid effused to take the place of lost vitreous only fulfills its purpose for a short time; vision may at first be extremely good, but soon deteriorates, so that at the end of a year or eighteen months all useful vision is lost, and the eye is found to be soft and shrinking, with large numbers of vitreous opacities, and in some cases detached retina.

With regard to the treatment by subcutaneous injections of pilocarpine, any opinion based on so small an experience as mine, consisting as it does of only seven cases, can be of little value, and might be very nisleading; four cases out of the seven appeared to receive some benefit, and I only quote the improvement that took place in these at Mr. Ford's distinct request:Case 1: A man aged forty-four; right eye blind from previous inflammatory trouble; left eye full of vitreous opacities; this eye improved from counting fingers at one metre to $\frac{6}{2}$, after four weeks' treatment. Case 2: A man aged twenty-four, with numerous vitreous opacities in the left eye ; improved from $\frac{B}{60}$ to $\frac{6}{1}$, after three weeks' treatment. Case 3: A girl aged twenty.two, with vitreous opacities in right eye ; has advanced from $\frac{4}{60}$ to ${ }^{\circ}$, after three weeks' treatment, which will be completed to-morrow (March 20th). Case 4. A woman aged fifty.four, with vitreous opacities in right eye ; improved from to to after twenty-two injections. (I am indebted to Mr. Folker, house surgeon to the Royal Westminster Ophthalmic Hospital, for the note of this case.) I trust at some future time, after a more extended trial of this form of treatment, to publish a detailed account of all my cases.

I am, Sirs, yours faitufully,

Gustavus HartridGe, F.R.C.S.

Surgeon to the Royal Westminster Ophthalmic Hospital, \&c. Green-street, Park-lane, W., March 19th, 1890.

\section{${ }^{\circ}$ PROLAPSE OF THE WALL OF THE STOMACH OF A HORSE INTO THE DUODENUM." \\ To the Editors of THE LANCET.}

SrRs,--In your issue of the 8 th inst. I observe that Mr. Spencer exhibited at the Pathological Society a specimen of prolapse of the cardiac portion of the stomach into the duodenum of a horse. The case in itself is unique, at least so far as I know, but Mr. Spencer's remarks as to vomiting in the horse detract materially from the value of his communication. He says: "Whilst the horse's stomach does not differ materially from man's, except in the intraabdominal osophagus, the animal hardly ever vomited, except when the stomach was ruptured. There was no vomiting in this case."

From what source Mr. Spencer obtained his information in reference to vomiting in the horse I know not, but he has been utterly misled, or he has himself arrived at a wrong con clusion. It I am not mistaken, the theory that vomiting is a sign of gastric rupture in the horse received the greatest amount of support from Bollinger; but it is, at the same time, an old theory, and in my view is opposed to all physical laws. I fail to see how a horse with ruptured stomach can vomit; he certainly could not, except on the assumption that the pressure on the intestines was sufficient to occlude the aperture produced by the rupture, and that simultaneously with this and with contraction of the walls of the stomach there was dilatation of the cardiac orifice of the cesophagus-a very improbable occurrence, seeing that the integrity of the gastric walls is done away with in such cases; and, I would ask, would not the amount of force required to propel the gastric contents up the csophagus be more likely to force the ingesta through the aperture in the stomach walls into the abdominal cavity? I have always taught that the act of vomiting is precedent to the gastric rupture, not subsequent; and on post-mortem examination we always find in cases of complete rupture that the contents of the stomach have been forced into the abdominal cavity, in which it becomes disseminated amongst the intestines, or entangled in the meshes of the omentum or mesentery, or of both. In all cases where the symptoms have indicated the existence of gastric rupture I have never seen vomiting, but I have frequently seen it-or attempts at vomiting-as a precedent phenomenon; and I have on various occasions seen horses vomit when suffering from gastric plethora, and never afterwards exhibit a sign of the existence of an organic lesion such as rupture. How Mr. Spencer could imagine that a horse with the cardiac portion of the stomach involuted into the duodenum could vomit I cannot comprehend.-I am, Sirs, yours truly, THOMAS WALLEY.

Royal Veterinary College, Edinburgh, March 10th, 1890.

\section{NORTHERN COUNTIES NOTES.}

\section{(From OUR OWN CORRESPONDENT.)}

\section{Newcastle.}

Sir JAMes Crichtor Browne had a hearty reception on his late visit to Newcastle. Many of his old friends in the north (and they are numerous) were glad to renew their acquaintance, and to see him looking so well. His lecture on Brain Structure was most attentively listened to by a large and appreciative audience, which, as might be expected, comprised a great number of practitioners and students. The chairman, Dr. F. Page, of this city, well expressed the feeling of the audience when he said they were proud of Sir James Crichton Browne's success and well-merited distinctions.

\section{Sunderland.}

At a meeting held at the Sunderland Infirmary last week some very satisfactory progress was reported. It was stated that, as a result of the visit to London of the deputation appointed for the purpose, the Ecclesiastical Commissioners had consented to increase their subscription from $£ 500$ to $£ 1000$ per annum, and that Miss Forster (one of the owners of the South Hetton Colliery) had generously offered to bear the cost of erection of the new isolation wards $(\mathfrak{f 6 0 0 )}$. Several other large contributions had been made to the infirmary, which will no doubt soon become fully equipped for its work.-The Eye Infirmary at Sunderland is about to receive a larger amount of support from the workmen of the district, who, at a representative meeting held at the institution, passed a resolution to devote one day's pay each during the year. This is to be deducted quarterly, and so it will be little felt by them, while it will amount to an important sum at the year's end. Besides, this mode of regularly subscribing by the workmen gives them a more direct interest in the charity.-The report of the Sunderland Provident Dispensary, read at the annual meeting last week, shows an enormous amount of work done during the past year. The number of prescriptions dispensed was 23,900 ; the number of visits paid by the medical staff was 16,000. The total income had been $f 1215$. The amount paid the medical officers was small-namely, $£ 600$, - considering that the committee have a balance of $£ 214$ in hand. 